\title{
An Electrochemical Aptasensor for the Detection of HER2 as a Breast Cancer Biomarker Based on Gold Nanoparticles-Aptamer Bioconjugates
}

\author{
Yeni Wahyuni Hartati ${ }^{1,2^{*}}$, Sari Syahruni ${ }^{1}$, Shabarni Gaffar ${ }^{1,2}$, Santhy Wyantuti ${ }^{1}$, \\ Muhammad Yusuf ${ }^{1,2}$, and Toto Subroto ${ }^{1,2}$ \\ ${ }^{1}$ Department of Chemistry, Faculty of Mathematics and Natural Sciences, Universitas Padjadjaran, \\ Jl. Raya Bandung-Sumedang Km. 21, Jatinangor, Sumedang 45363, Indonesia
}

${ }^{2}$ Research Center of Molecular Biotechnology and Bioinformatics, Universitas Padjadjaran, Jl. Singaperbangsa No. 2, Bandung 40132, Indonesia

\section{*Corresponding author:}

email: yeni.w.hartati@unpad.ac.id

Received: June 28, 2021

Accepted: September 5, 2021

DOI: $10.22146 / \mathrm{ijc} .67124$

\begin{abstract}
Inaccurate diagnoses contributes to the high mortality rate of breast cancer. Human epidermal growth factor receptor 2 (HER2) is overexpressed in breast cancer tumors at around 20-30\%. This study aims to develop an electrochemical biosensor for HER2 based on a gold nanoparticle-aptamer bioconjugate (AuNP@HER2 aptamer) and investigate the interaction between DNA aptamer and HER2 using computational methods. The bioconjugate was synthesized using maleimide and polyethylene glycol as a linker. The $-\mathrm{NH}_{2}$ group of cysteamine that modified the gold electrode can form a covalent bond with the bioconjugate maleimide. The interaction of the bioconjugated aptamer with HER2 was measured electrochemically based on the $\left[\mathrm{Fe}(\mathrm{CN})_{6}\right]^{3-14-}$ redox system. The limit of detection, the linear range of HER2, precision, and accuracy in this study were

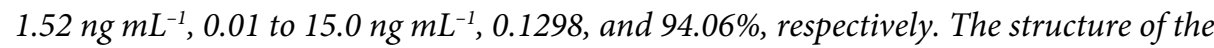
DNA aptamer was modeled using mFold, Assemble2, and Chimera, with the interaction between the DNA aptamer and HER2 explored by NPDock. The modeling of the aptamer with HER2 showed that electrostatic interactions dominated the attractive forces. The resulting interaction pattern can be used as a template to improve the binding energy of the aptamer, thus providing insight into the development of aptamer-based biosensors.
\end{abstract}

Keywords: electrochemical aptasensor; HER2; aptamer; voltammetry; molecular modeling; breast cancer

\section{- INTRODUCTION}

Breast cancer has a high mortality rate, accounting for approximately $15 \%$ of cancer deaths among women [1]. Moreover, almost $70 \%$ of the cases were detected late. Hence treatment outcomes are poor. Earlier diagnosis would improve the chance of successful therapy by $80-$ $90 \%$ [2]. Therefore, efforts are ongoing to develop early detection methods for breast cancer.

Human epidermal growth factor receptor 2 (HER2) protein is a breast cancer biomarker in the form of three domains; a transmembrane region, an intracellular tyrosine kinase domain, and an extracellular domain that can be released into the bloodstream [3-5]. The HER2 protein concentration in serum is less than $15 \mathrm{ng} \mathrm{mL} L^{-1}$
(4-14 $\left.\mathrm{ng} \mathrm{mL}^{-1}\right)$ in healthy women and overexpressed in active surveillance of patients at risk or in treatment at about $>15 \mathrm{ng} \mathrm{mL}^{-1}$ [6-7].

The determination of HER2 protein based on electrochemical techniques has been widely developed and reported in the last decade. Electrochemical methods are preferable because of their rapid detection, high sensitivity, and selectivity, as well as the low limit of detection [8-11]. The use of aptamer as the biorecognition molecule that can specifically recognize the protein target in the sample has attracted much attention because of its stability, synthetic portability, and various functional design [12-14]. The methods for obtaining an aptamer such as the systematic evolution of 
ligands by enrichment exponential (SELEX) [15-16], kinetics capillary electrophoresis as the equilibrium and nonequilibrium capillary electrophoresis of equilibrium mixtures (ECEEM and NECEEM) [17-19], and rational design in-silico [20-21] have been developed and applied in electrochemical aptasensors.

Modification of electrodes with aptamers is a crucial process in electrochemical aptasensor research. Various electrodes have been modified using various materials to obtain high sensitivity of the aptasensors in order to detect HER2 as a breast cancer biomarker [22]. A homemade screen-printed electrode modified with polyL-lysine has been used for immobilizing HER2 aptamer by electrostatic adsorption. The biosensor exhibited an excellent interaction between the aptamer and the target protein [3]. HER2 aptamer was immobilized by a selfassembled monolayer (SAM) on the surface of the gold electrode (GE), which was pretreated with 3mercaptopropionic acid (MPA), and the sensor was able to detect HER2 concentrations ranging from $10^{-5}-10^{2} \mathrm{ng}$ $\mathrm{mL}^{-1}$ by using electrochemical impedance spectroscopy technique [19]. The sensing platforms were also developed on gold screen-printed electrodes via SAM between the thiolated DNA aptamer of HER2 and 1mercapto-hexanol, and also a ternary SAM between the same aptamer and 1,6-hexanediol [23]. A new bimetallic ZrHf metal-organic framework (ZrHf-MOF) embedded with abundant carbon dots (CDs) (denoted as CDs@ZrHf-MOF) could be applied as the scaffold for anchoring aptamer strands to determine HER2 and living HER2-overexpressed MCF-7 cells [24].

A labeled electrochemical aptasensor using exonuclease recycling amplification and host-guest recognition system was reported to detect HER2. The HER2 aptamer was firstly hybridized with ferrocenelabeled DNA/Au nanospheres ( $\mathrm{FcNS}$ ) and then bound with the HER2 target. The released FcNS homogeneously hybridized with horseradish peroxidase-labeled DNA/Au nanospheres [25]. A label-free capacitive aptasensor was developed to capture HER2 protein by anti-HER2 ssDNA aptamers functionalized on interdigitated microelectrodes of a capacitor. The aptasensor response was measured by the non-Faradaic impedance spectroscopy (nFIS) method based on changes that occurred due to charge distribution upon the interaction of aptamer-protein molecules against the applied AC frequency (50$350 \mathrm{MHz}$ ) [26].

A sandwich-type electrochemical aptasensor to detect HER2 was constructed using a combination of tetrahedral DNA nanostructures (TDNs) - adapter as recognition probes and $\mathrm{Mn}_{3} \mathrm{O}_{4} / \mathrm{Pd} @ \mathrm{Pt}$ nanozymes/ horseradish peroxidase (HRP) as signal nanoprobes on the GE. The designed $\mathrm{Mn}_{3} \mathrm{O}_{4} / \mathrm{Pd} @ \mathrm{Pt} / \mathrm{HRP}$ nanoprobe was used to amplify the biosensor signal via catalyzing the oxidation of hydroquinone (HQ) with hydrogen peroxide $\left(\mathrm{H}_{2} \mathrm{O}_{2}\right)$ [27]. The biotinylated specific aptamers to HER2 positive receptor were immobilized at the neutravidin layer chemisorbed at the gold surface of the thickness-shear mode acoustics method (TSM) transducer. The LOD of the proposed aptasensor reached 550 cells $\mathrm{mL}^{-1}$ [28].

A bioconjugate-based aptamer for detecting HER2 was reported using gold nanorod@Pd superstructuresaptamer HER2-horseradish peroxidase (GNR@Pd SSsApt-HRP) as a signal probe to enable signal amplification. The aptasensor was constructed by immobilizing DNA tetrahedron with expanded aptamer on the GE [29]. Nanomaterial-based bioconjugate can provide benefits such as improving the ability of sensing by increasing sensitivity, lowering LOD, and being fast and simple. Furthermore, polyethylene glycol (PEG) can increase the solubility of reagents and bioconjugates [30-33].

The current study aims to develop an aptasensor based on a gold nanoparticle (AuNP@HER2 aptamer) bioconjugate using the PEG as a linker via maleimide binding. The response of HER2 was measured using differential pulse voltammetry techniques from the $\left[\left[\mathrm{Fe}(\mathrm{CN})_{6}\right]^{4-/ 3-}\right.$ redox system. Furthermore, the molecular interaction between the aptamer and HER2 was investigated using a molecular docking method, providing valuable insight into developing aptamerbased biosensors for cancer diagnosis. 


\section{- EXPERIMENTAL SECTION}

\section{Materials}

HER2 antigen, 1-ethyl-3-(3-dimethyl aminopropyl) carbodiimide (EDC), 3-aminopropyltrimethoxysilane (APTMS), 3-mercaptopropionic acid (MPA), poly(ethylene glycol)- $\alpha$-maleimide- $\omega$-NHS ester (PEGNHS-Mal), cysteamine, N-hydroxy succinimide (NHS), 2-iminothiolane (Traut's reagent), potassium ferricyanide $\left(\mathrm{K}_{3}\left[\mathrm{Fe}(\mathrm{CN})_{6}\right]\right)$, bovine serum albumin (BSA), ethanol $\left(\mathrm{C}_{2} \mathrm{H}_{6} \mathrm{O}\right)$, sodium borohydride $\left(\mathrm{NaBH}_{4}\right)$, citric acid $\left(\mathrm{NaC}_{6} \mathrm{H}_{7} \mathrm{O}_{7}\right)$, and sodium ethylenediaminetetraacetate ( $\mathrm{Na}_{2}$ EDTA) were purchased from Sigma-Aldrich. A 99\% gold bar was obtained from PT, Antam, Indonesia. The thiol-terminated ssDNA aptamer (5'-/HSC6/CTT CTG CCC GCC TCC TTC CTG GGG CCT GGA TAC GGA TTG GTA AGG ATT AGT AGG GGG CAT AGC TGG AGA CGA GAT AGG CGG ACA CT-3') was synthesized by Integrated DNA Technologies (USA). Phosphatebuffered saline (PBS) solutions were prepared by dissolving hydrogen phosphate $\left(\mathrm{Na}_{2} \mathrm{HPO}_{4} \cdot 12 \mathrm{H}_{2} \mathrm{O}\right)$, sodium hydroxide $(\mathrm{NaOH})$, sodium chloride $(\mathrm{NaCl})$, and potassium chloride ( $\mathrm{KCl})$ (Merck).

\section{Instrumentation}

Electrochemical measurements were performed by differential pulse voltammetry (DPV) using a Metrohm $\mu$ Autolab potentiostat. All experiments were conducted using a three-electrode system, with the GE as a working electrode fabricated from a $0.5 \mathrm{~cm}$ gold wire (diameter $0.5 \mathrm{~mm}$ ) and copper wires. In addition, a platinum wire and $\mathrm{Ag} / \mathrm{AgCl}$ electrode (Metrohm) were used as a counter and reference electrode, respectively.

\section{Procedure}

\section{Synthesis of gold nanoparticles (AuNP)}

Briefly, $0.5 \mathrm{~mL}$ of $0.1 \mathrm{M}$ sodium citrate $\left(\mathrm{Na}_{3} \mathrm{C}_{6} \mathrm{H}_{5} \mathrm{O}_{7}\right)$ was added to $1 \mathrm{mM}$ of $\mathrm{HAuCl}_{4}$ under constant stirring.
Then, $80 \mu \mathrm{L}$ of $\mathrm{NaBH}_{4} 0.1 \mathrm{M}$ was added dropwise, and the color of the solution turned red/purple. AuNPs were characterized using UV-Vis spectrophotometry and showed the maximum absorption at 520-530 nm.

\section{Preparation of the bioconjugate}

The AuNP-aptamer bioconjugate was synthesized adopting the metal oxide-antibody bioconjugate preparation procedure as previously described [32-33]. First, the amino modification of the AuNP surface was performed to form a stable AuNP. Briefly, $10 \mathrm{~mL}$ of AuNP solution was modified with $25 \mu \mathrm{L}$ of 3aminopropyltrimethoxysilane (APTMS) before the APTMS-coated AuNP was sonicated to prevent aggregation. The aptamer was then conjugated to AuNP using NHS-PEG-Mal as a spacer. First, $31 \mathrm{mg}$ of NHSPEG-Mal was added to the amino-AuNP solution to obtain the sulfhydryl-reactive group of pegylated AuNP, then $200 \mu \mathrm{L}$ of the pegylated AuNP was incubated with the thiolated aptamer $\left(5 \mu \mathrm{g} \mathrm{m}^{-1}\right)$ overnight.

\section{Optimization of parameters using the Box-Behnken design}

The MPA incubation time $\left(\mathrm{X}_{1}\right)$, bioconjugate incubation time $\left(\mathrm{X}_{2}\right)$, and the concentration of aptamer $\left(\mathrm{X}_{3}\right)$ were optimized via different levels; the lowest level $(-1)$, intermediate $(0)$, and highest level $(+1)$, as shown in Table 1. Each measurement was processed, and the optimal value for each factor was determined using the Box-Behnken experimental design with the Minitab 18 program. All measurement was carried out using the differential pulse voltammetry technique.

\section{Fabrication of the aptasensor}

Before immobilizing the bioconjugate onto the GE surface, the GE was polished with $\mathrm{Al}_{2} \mathrm{O}_{3}$ and ultrasonically cleaned with ethanol and double-distilled water $\left(\mathrm{ddH}_{2} \mathrm{O}\right)$ for $3 \mathrm{~min}$. Then, the GE was immersed in piranha solution for $5 \mathrm{~min}$ to remove residues from the

Table 1. Optimization of experimental conditions using the Box-Behnken design

\begin{tabular}{llrrr}
\hline \multirow{2}{*}{ Factors } & \multirow{2}{*}{ Unit } & \multicolumn{3}{c}{ Level } \\
\cline { 3 - 5 } & & 10 & 0 & +1 \\
\hline MPA incubation time & $\min$ & 25 & 4 \\
Time of bioconjugate immobilization & $\min$ & 30 & 60 & 90 \\
Level of aptamer & $\mu \mathrm{g} \mathrm{mL} \mathrm{mL}^{-1}$ & 5 & 15 & 25 \\
\hline
\end{tabular}


surface and washed several times with $\mathrm{ddH}_{2} \mathrm{O}$.

The GE was incubated in 0.1 M MPA solution for $40 \mathrm{~min}$ at room temperature, then rinsed with $\mathrm{dd}_{2} \mathrm{O}$ before incubation in $40 \mu \mathrm{L}$ of $0.1 \mathrm{M}$ EDC:NHS solution for $60 \mathrm{~min}$ and washed with $\mathrm{dd}_{2} \mathrm{O}$. EDC:NHS coupling was carried out to activate the carboxyl group of MPAmodified GE. After rinsing with $\mathrm{ddH}_{2} \mathrm{O}$, the $\mathrm{GE}$ was incubated in $0.1 \mathrm{M}$ cysteamine solution for $60 \mathrm{~min}$ at room temperature to form the thiol end group, a maleimide-reactive group on the GE surface. Finally, the GE was rinsed with $\mathrm{ddH}_{2} \mathrm{O}$, and the modified GE was incubated in $40 \mu \mathrm{L}$ of bioconjugate for $90 \mathrm{~min}$ at room temperature. The double bond of the free maleimide group of the bioconjugate reacted with the thiol group of cysteamine to form a covalent bond. The unbonded bioconjugate was washed with PBS (pH 7.4).

The sensor was incubated in 1\% BSA solution for $60 \mathrm{~min}$ at $37^{\circ} \mathrm{C}$ to block unspecific binding on the $\mathrm{GE}$ surface, then rinsed with $\mathrm{ddH}_{2} \mathrm{O}$ several times. Next, the GE was incubated in different concentrations of HER2 solution for $60 \mathrm{~min}$ at room temperature and washed with PBS. Finally, the biosensors were characterized in $10 \mathrm{mM}$ of Fe $(\mathrm{CN})_{6}{ }^{3-/ 4-}$ by DPV, a redox probe solution from -0.6 to $+0.5 \mathrm{~V}$ with a scan rate of $50 \mathrm{mV} \mathrm{s}^{-1}$.

\section{Prediction of the secondary structure of the aptamer}

The secondary structure of the DNA aptamer was predicted using the mfold web server (http://unafold.rna.albany.edu/?q=mfold/DNA-FoldingForm) [34]. The folding temperature was measured at $37^{\circ} \mathrm{C}$, and the physiological ionic conditions were fixed at $\left[\mathrm{Na}^{+}\right]=1 \mathrm{M}$ and $\left[\mathrm{Mg}^{2+}\right]=0 \mathrm{M}$. The number of computed folds was 50 , and the distance between the paired base was unlimited [35]. The most stable secondary structure of DNA aptamer was selected based on the minimum $\Delta \mathrm{G}$.

\section{Construction of the aptamer 3D structure}

The aptamer 3D structure was modeled using Assemble2 [36] and visualized using Chimera [37]. The structure was constructed based on the RNA model and refined using 100 times iterations. First, a hydrogen atom was added to the RNA model. Then, the RNA model was manually changed into a DNA model by modifying uracil to thymine via replacing the $\mathrm{H} 5$ atom with a methyl group and ribose sugar into deoxyribose using BIOVIA Discovery Studio Visualizer 4.5 [38].

\section{Prediction of the interaction between the aptamer and HER2}

The electrostatic potential on the surface of HER2 was computed through the PDB2PQR server [37] using the APBS program (http://nbcr-222.ucsd.edu/pdb2pqr 2.0.0/) [39]. The interaction between the aptamer and HER2 was predicted using NPDock (http://genesilico.pl/NPDock) [40], a molecular docking program specially built for a protein-nucleotide system. The HER2 binding site was determined at the protein electropositive region, and the decoys number was set to 20,000 with a minimum interface contact of one residue. Monte Carlo refinement was performed using 1,000 steps of simulation, with the temperature in the last step set to $295 \mathrm{~K}$.

\section{- RESULTS AND DISCUSSION}

\section{Aptasensor Based on Bioconjugate}

Fig. 1 depicts a scheme of the aptasensor based on a bioconjugate aptamer as a sensing element. Previous research showed that PEG is a compatible linker for bioconjugation of AuNP and biorecognition molecules [32-33] and is required to provide space to bind more aptamers to AuNP, as can be seen in Fig. 1. The thiol groups of aptamers were covalently attached to the unsaturated bond of maleimides linked to the nanoparticles to form the bioconjugates. The double bond in the free maleimides of the bioconjugate readily reacts with the thiol groups from cysteamine on the electrode to form a stable carbon-sulfur bond. Then the aptamer is ready to catch the HER2 biomarker.

\section{Characterization of the Aptasensor}

Fig. 2 shows the differential pulse voltammogram of each modification step of the GE surface. The maximum reduction current peak was observed in the bare GE $(241 \mu \mathrm{A})$ at the potential of about $150 \mathrm{mV}$ vs. $\mathrm{Ag} / \mathrm{AgCl}(2 \mathrm{a})$. The modification of the GE surface with MPA and cysteamine slightly reduced the peak current to $234 \mu \mathrm{A}(2 \mathrm{~b})$ and drifted the potential to $146 \mathrm{mV}$ due to the formation of carboxyl groups which facilitate electron 


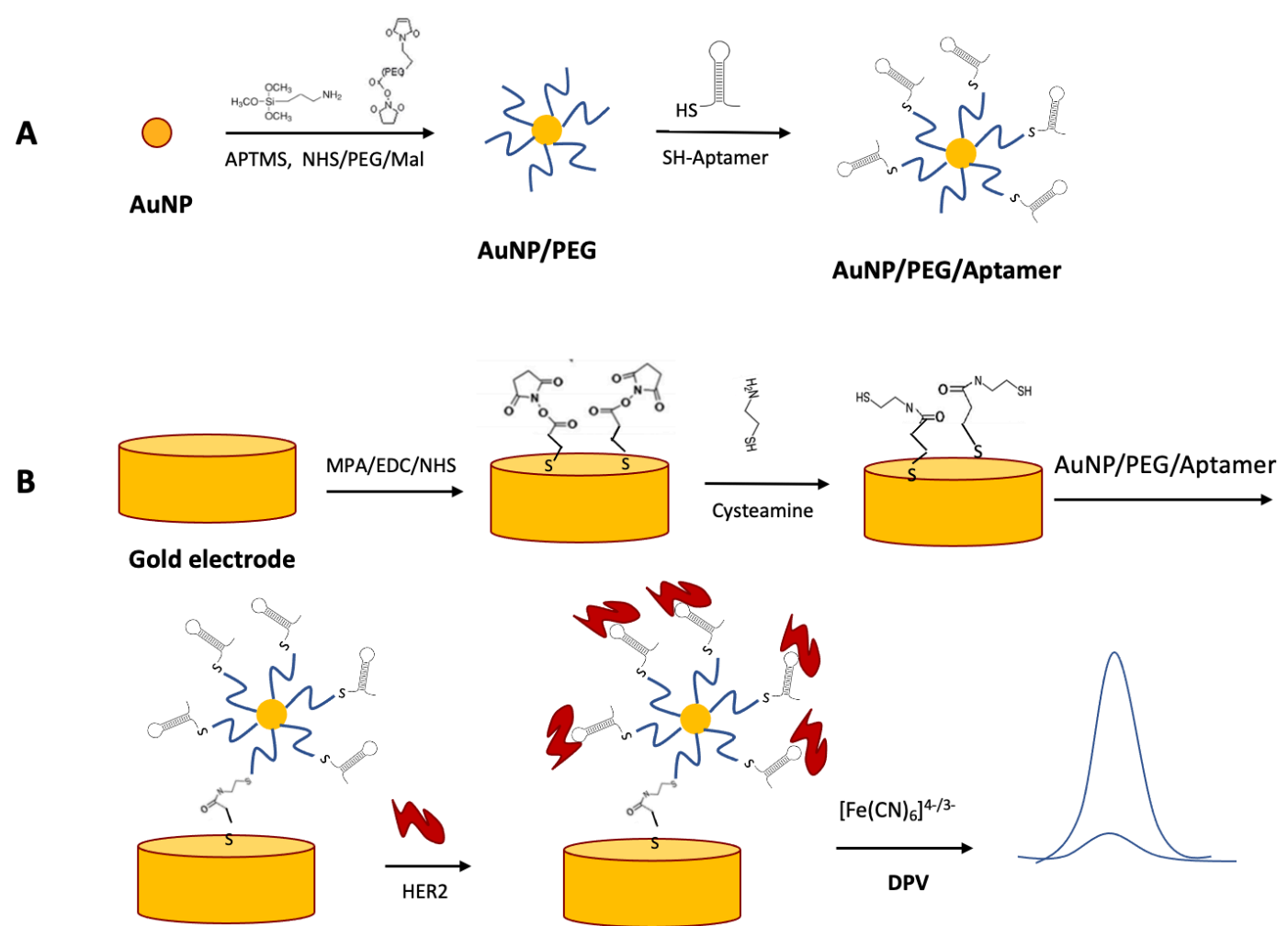

Fig 1. Scheme of the aptasensor for detection of HER2 biomarker

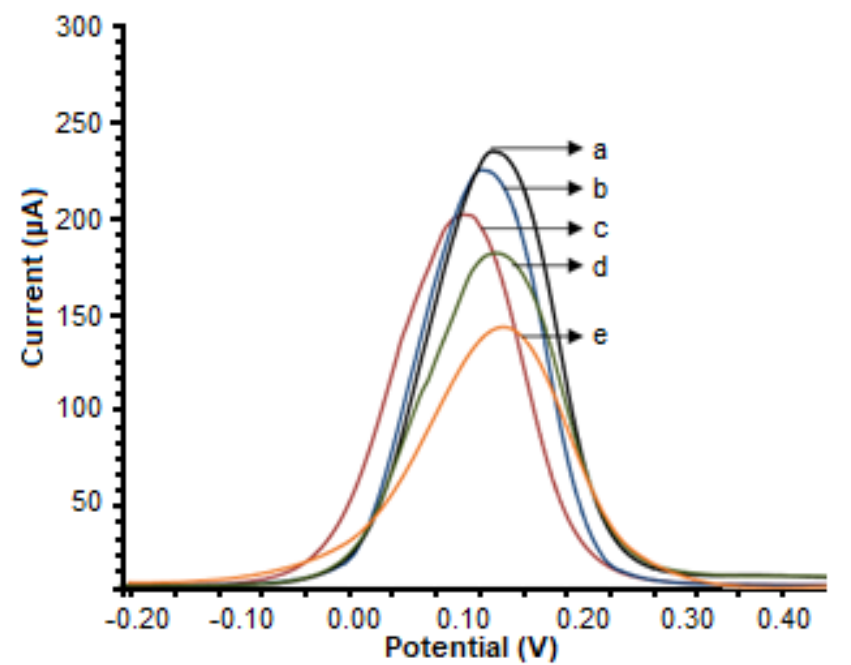

Fig 2. Voltammogram of each modification step of the GE bare (a), GE/MPA/Cys (b), GE/MPA/Cys/ bioconjugate (c), GE/MPA/Cys/bioconjugate/BSA (d), and GE/MPA/ Cys/bioconjugate/BSA/HER-2 (e). The response was observed using $10 \mathrm{mM}\left[\mathrm{Fe}(\mathrm{CN})_{6}\right]^{3-14}$, recorded at -0.2 to $+0.4 \mathrm{~V}$, and a scan rate of $50 \mathrm{mV} \mathrm{s}^{-1}$

transfer between the $\left[\mathrm{Fe}(\mathrm{CN})_{6}\right]^{4-/ 3-}$ and the electrode. In addition, the dangling thiol group of GE/MPA/ cysteamine can react with the double bond of the free maleimide group of the bioconjugate. Immobilization of the bioconjugate at the electrode surface shifts the potential to the left due to the bioconjugate containing AuNP, which can easily facilitate the electron transfer of the $\left[\mathrm{Fe}(\mathrm{CN})_{6}\right]^{4-/ 3-}$ redox system. However, the nonelectroactive biomolecules in the bioconjugate caused the $\left[\mathrm{Fe}(\mathrm{CN})_{6}\right]^{4-/ 3-}$ peak current to decrease to $201 \mu \mathrm{A}$ (2c). The blocking step with BSA also reduced the current to $176 \mu \mathrm{A}$ and shifted the potential to $151 \mathrm{mV}$ (2d). Finally, incubation of $5 \mathrm{ng} \mathrm{mL}^{-1}$ HER2 protein was monitored and observed in a reduction current of 147 $\mu \mathrm{A}$ at $151 \mathrm{mV}(2 \mathrm{e})$, indicating successful immobilization of each molecule on the GE surface.

\section{Experimental Optimization}

Three factors, namely MPA incubation time $\left(\mathrm{X}_{1}\right)$, bioconjugate incubation time $\left(\mathrm{X}_{2}\right)$, and the concentration of aptamer $\left(\mathrm{X}_{3}\right)$, were optimized using the Box-Behnken experimental design with the Minitab program 18. The experiments were performed 15 times in duplicate resulting in 30 experiments, and the 
measurements were recorded in Minitab 18 to obtain the maximum current value. From the experimental data, the regression equation was as follows:

$Y=95.2-6.06 X_{1}+1.80 X_{2}-1,96 X_{3}+0.0459 X_{1} X_{2}-$ $0.0101 \mathrm{X}_{2} \mathrm{X}_{2}-0.018 \mathrm{X}_{3} \mathrm{X}_{2}+0.0376 \mathrm{X}_{1} \mathrm{X}_{2}+0.1329 \mathrm{X}_{1} \mathrm{X}_{3}-$ $0.0542 \mathrm{X}_{2} \mathrm{X}_{3}$

The above equation shows that the MPA incubation time and the concentration of aptamers have negative coefficients and decreased the response, while the bioconjugate incubation time has a positive value and increased the response. The ANOVA analysis of the BoxBehnken experiments revealed the $\mathrm{P}$-value of each factor as $\mathrm{X}_{1}=0.355 ; \mathrm{X}_{2}=0.030 ;$ and $\mathrm{X}_{3}=0.019$. The $\mathrm{P}$-value of $\mathrm{X}_{2}$ and $\mathrm{X}_{3}$ is $\leq 0.05$, indicating that the factors are significant. The optimum experimental conditions determined from the Box-Behnken data were: MPA incubation for $40 \mathrm{~min}$, the bioconjugate incubation time for $90 \mathrm{~min}$, and aptamer concentration of $5 \mu \mathrm{g} \mathrm{mL} \mathrm{m}^{-1}$. The optimization data is available in the Supplementary Information.

\section{Analytical Performance of the Aptasensor}

The responses of the aptamer-based biosensor to the various HER2 concentrations were investigated at optimal experimental conditions. The voltammogram at

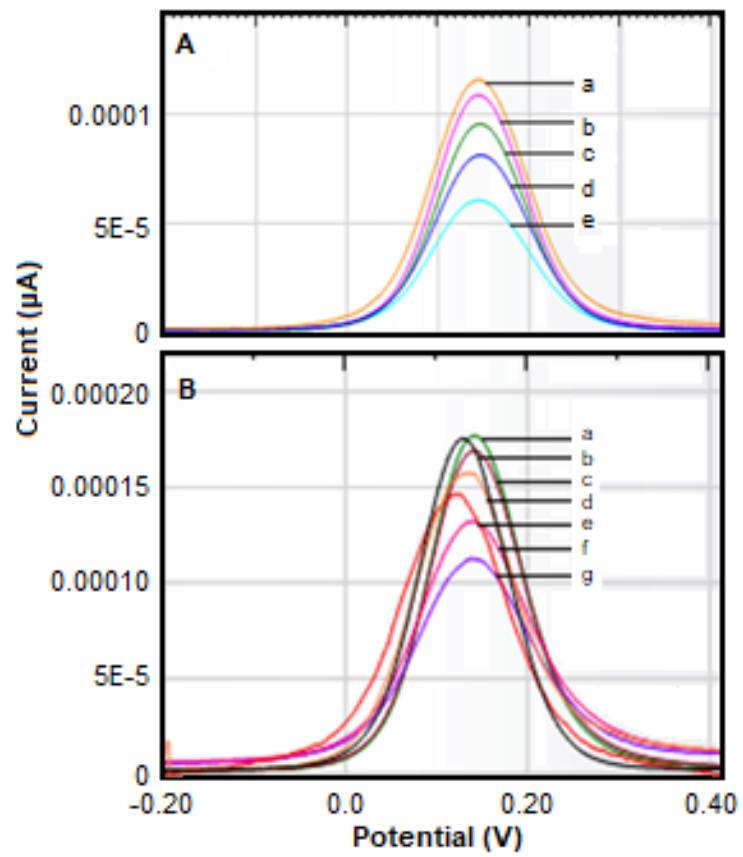

the potential range of -0.2 to $+0.4 \mathrm{~V}$ in Fig. $3 \mathrm{~A}$ and $3 \mathrm{~B}$ shows that the current peak reduced with increasing HER2 level. This was due to the inhibition of the electron transfer between the redox system and the electrode by binding non-electroactive HER2 to the aptasensor surface.

The calibration curve is linear over two concentration ranges, from 0.01 to $15.0 \mathrm{ng} \mathrm{mL}^{-1}$ and 15.0 to $100.0 \mathrm{ng} \mathrm{mL}^{-1}$, as shown in Fig. 3C. The corresponding calibration regression equations for lower and higher concentration ranges were $\Delta \mathrm{I}=4.1998$ [HER2] - 0.2876 with a coefficient correlation $\left(\mathrm{R}^{2}\right)$ of 0.995 , and $\Delta \mathrm{I}=$ 0.6782 [HER2] + 52.217 with a coefficient correlation $\left(\mathrm{R}^{2}\right)$ of 0.995 , respectively

The limit of detection (LOD) was evaluated using the blank signal, $y_{B}$, plus three standard deviations of the blank, $s_{B}$. The blank signal $y_{в}$ is the intercept of a calibration curve, and $s_{\mathrm{B}}$ is obtained as random errors in the $y$-direction (41). The LOD was found at HER2 concentration level of $1.52 \mathrm{ng} \mathrm{mL}^{-1}$, in the linear range of 0.01 to $15.0 \mathrm{ng} \mathrm{mL} \mathrm{m}^{-1}$. This LOD was higher than several previous aptamer-based biosensors, as can be seen in Table 2. The complexity of the spacer may cause this difference. However, the LOD in this study was lower compared to our previous

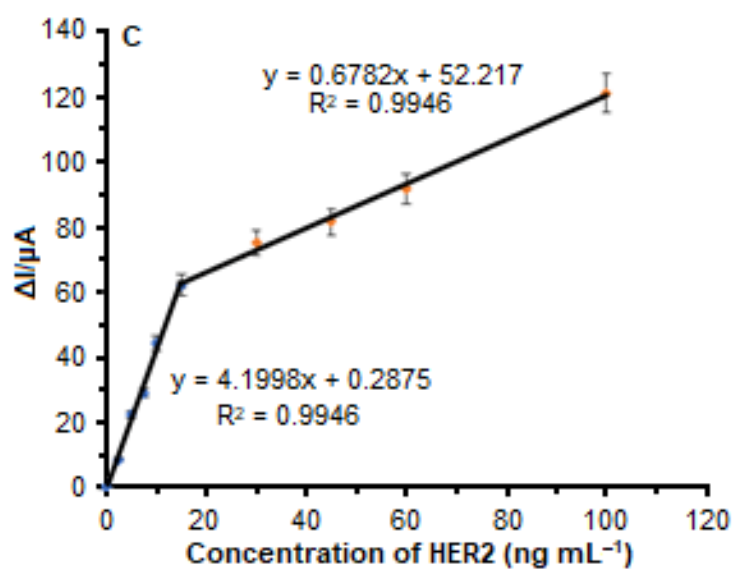

Fig 3. A and B: Voltammogram of various concentrations of HER2 0.01 to $15.0 \mathrm{ng} \mathrm{mL} \mathrm{m}^{-1}$, and 15.0 to $100.0 \mathrm{ng} \mathrm{mL}^{-1}$. C: Calibration curve of HER2 from 0.0 to $100 \mathrm{ng} \mathrm{mL}^{-1}$ 
Table 2. The comparison of HER2 detection by using aptasensors

\begin{tabular}{|c|c|c|}
\hline Technique & LOD & Reference \\
\hline SPCE@L-lysine & $3.0 \mathrm{ng} \mathrm{mL}^{-1}$ & {$[3]$} \\
\hline GE-MPA & $5.0 \mathrm{ng} \mathrm{mL}^{-1}$ & [19] \\
\hline GE-MCH and GE- & 172 and $179 \mathrm{pg} \mathrm{mL}^{-1}$ & [20] \\
\hline Bimetallic ZrHf-MOF - CDs@ZrHf-MOF & $19 \mathrm{fg} \mathrm{mL}^{-1}$ & [24] \\
\hline Exonuclease recycling amplification and host-guest recognition & $4.9 \mathrm{ng} \mathrm{mL}^{-1}$ & [25] \\
\hline $\begin{array}{l}\text { Non-Faradaic impedance spectroscopy (nFIS) of a microelectrode } \\
\text { capacitive aptasensor }\end{array}$ & $0.2-2.0 \mathrm{ng} \mathrm{mL}^{-1}$ (Dynamic range) & [26] \\
\hline $\begin{array}{l}\text { A tetrahedral DNA nanostructure (TDNs) - adapter as recognition } \\
\text { probes and Mn3O4/Pd @ Pt nanozymes/HRP }\end{array}$ & $0.08 \mathrm{ng} \mathrm{mL}^{-1}$ & [27] \\
\hline Thickness shear mode acoustics method (TSM) & 550 cells $\mathrm{mL}^{-1}$ & [28] \\
\hline $\begin{array}{l}\text { Gold nanorod@Pd superstructures-aptamer HER2-horseradish } \\
\text { peroxidase (GNR@Pd SSs-Apt-HRP) }\end{array}$ & $0.15 \mathrm{ng} \mathrm{mL}^{-1}$ & {$[29]$} \\
\hline GE- Gold-aptamer bioconjugate & $1.52 \mathrm{ng} \mathrm{mL}^{-1}$ & This work \\
\hline
\end{tabular}

study based on the antibody biosensor (an immunosensor) for HER2 detection (31-42) because of the conjugation of the aptamer with gold nanoparticles which increased electron transfer and signal amplification. The advantage of the use of aptamer as a sensing element is that it is much cheaper than antibodies. In addition, this aptasensor was able to still distinguish the concentration of HER 2 in cancer and normal cells, which were 17.7 and $12.2 \mathrm{ng} \mathrm{mL}^{-1}$, respectively (43). The precision of $5.0 \mathrm{ng} \mathrm{mL} \mathrm{mL}^{-1}$ HER2 represented by the coefficient of variance was 0.1298 , and the accuracy was $94.06 \%$ representing the percentage of the measured concentration value to the true concentration value ratio.

\section{Modeling Interaction}

The anti-HER2 ssDNA aptamer used in this study was retrieved as previously reported [44], and the model structure with the lowest DG of $-6.15 \mathrm{kcal} \mathrm{mol}^{-1}$ was selected for this study (Fig. 4). The aptamer is composed of a negatively charged phosphate backbone. Therefore, the binding site of the aptamer in the HER2 structure is expected to be electropositive. For this reason, the crystal structure of HER2 (PDB ID 1N8Z) was submitted to the PDB2PQR server to calculate the electrostatic potential on the protein surface using the APBS method, revealing that the electropositive part of HER2 was located in the upper region of HER2 (Fig. 5A) composed of a striking

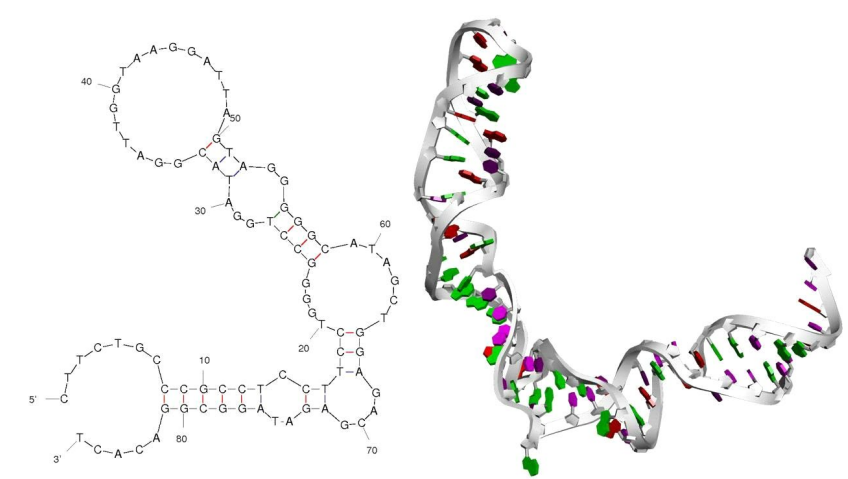

Fig 4. The secondary structure (left) and 3D structure (right) of the anti-HER2 aptamer

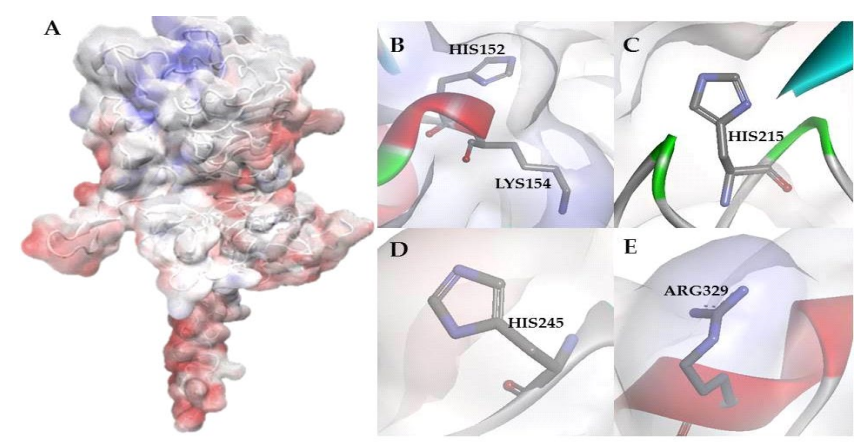

Fig 5. The electrostatic potential of HER2 from the APBS program. The electronegative and electropositive surfaces are represented by red and blue colors, respectively, with the electropositive part of HER2 located in the upper region of HER2. (A) His152, Lys153 (B), His215 (C), His245 (D) and Arg329 (E) 


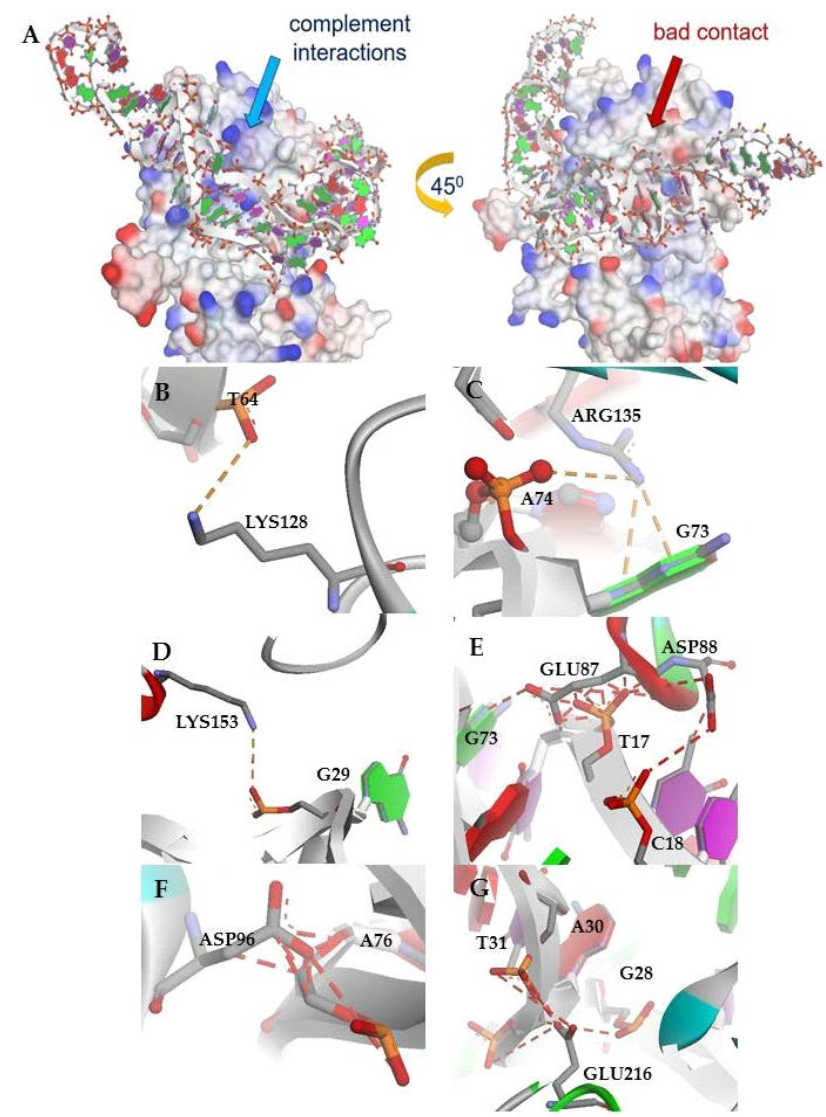

Fig 6. Complement interactions between the aptamer and HER2 (left) and the bad contacts in the other part of HER2 (right) (Fig. A). Acidic and basic residues are visualized in the red and blue colored surfaces, respectively. The orange dashed line shows the electrostatic interaction, the residues are Lys128 (Fig. B), Arg135 (Fig. C), and Lys135 (Fig. D). The red shows the unfavorable interactions dashed line with negatively charged residues, such as Glu87, Asp88 (Fig. B), Asp96 (Fig. F), and Glu216 (Fig. G)

lysine, arginine, and histidine, that was His152 (Fig. 5B), Lys153 (Fig. 5B), His215 (Fig. 5C), His245 (Fig. 5D), and Arg329 (Fig. 5E).

NPDock predicted the interaction between the aptamer and HER2, showing that the aptamer binds to the positively charged residues of HER2 (Fig. 6A), and the electrostatic interaction dominated the attractive forces, such as Lys128 (Fig. 6B), Arg135 (Fig. 6C), and Lys153 (Fig. 6D). The computed binding energy was -8.0 $\mathrm{kcal} / \mathrm{mol}$. Interestingly, not all aptamers interacted with the complement region. A few terminal nucleotides were in bad contacts, interacting with an electronegative patch on the surface of HER2. Therefore, it is predicted that the moderate binding of this aptamer is due to the unfavorable interactions with negatively charged residues, such as Glu87, Asp88 (Fig. 6E), Asp96 (Fig. 6F), and Glu216 (Fig. 6G).

Further optimization of this aptamer by removing the terminal part that interacts with those acidic residues is expected to improve its binding affinity to HER2. It is worth noting that the affinity of this aptamer to HER2 by the NECEEM method was $48 \%$ of binding affinity. However, the results of in vitro selectivity tests for representative molecules that might interfere with their interaction with HER2, including IgG, plasmid DNA, RNA, and glucose, indicated less than 10\% interaction [31].

\section{- CONCLUSION}

An aptasensor to detect HER2, a validated breast cancer biomarker, was developed using a bioconjugate to improve the surface area for better immobilization of the aptamer onto a gold electrode. The detection limit was $1.52 \mathrm{ng} \mathrm{mL}^{-1}$, and the system was able to distinguish between different concentrations of HER2 in normal and cancer cells. Modeling the interaction between the aptamer and HER2 showed that electrostatic interactions dominated the attractive forces, and any unfavorable interactions could be further optimized to improve the binding affinity of this aptamer to HER2. The resulting interaction pattern can be used as a template to improve the binding energy of the aptamer, providing an insight into the development of aptamerbased biosensors for other diseases. The results revealed a promising and sensitive tool capable of detecting HER2 protein in human serum with albumin depletion, aiding in the molecular diagnosis of breast cancer. Furthermore, this proposed strategy presented good reliability and applicability in analyzing human serum samples, showing great potential for applications in the early diagnosis of breast cancer.

\section{- ACKNOWLEDGMENTS}

This research was supported by the Ministry of Research, Technology and Higher Education, Republic 
of Indonesia, through the Research Grant of Skema Penelitian Terapan Unggulan Perguruan Tinggi, No. 1129/UN6.D/LT/2018, and Academic Leadership Grant Universitas Padjadjaran No. 2295/UN.6.D/KS/2018.

\section{- AUTHOR CONTRIBUTIONS}

YWH designed the experiment, SS conducted the experiment, MY conducted the DFT calculations, YW H, SG, and SW supervised, wrote, and revised the manuscript. TS was the funding leader of ALG. All authors agreed to the final version of this manuscript.

\section{- REFERENCES}

[1] WHO, 2014, Cancer Country Profile, World Health Organization, Geneva, Switzerland.

[2] American Cancer Society, 2020, Understanding a Breast Cancer Diagnosis: Survival Rates for Breast Cancer, https://www.cancer.org/cancer/breast-cancer/ understanding-a-breast-cancer-diagnosis/breastcancer-survival-rates.html, accessed on October 8, 2020.

[3] Bezerra, G., Córdula, C., Campos, D., Nascimento, G., Oliveira, N., Seabra, M.A., Visani, V., Lucas, S., Lopes, I., Santos, J., Xavier, F., Borba, M.A., Martins, D., and Lima-Filho, J., 2019, Electrochemical aptasensor for the detection of HER2 in human serum to assist in the diagnosis of early stage breast cancer, Anal. Bioanal. Chem., 411 (25), 6667-6676.

[4] Zhang, X.H., and Xiao, C., 2018, Diagnostic value of nineteen different imaging methods for patients with breast cancer: A network meta-analysis, Cell. Physiol. Biochem., 46 (5), 2041-2055.

[5] Khanjani, F., Sajedi, R.H., and Hasannia, S., 2018, Rapid screening of drug candidates against EGFR/HER2 signaling pathway using fluorescence assay, Anal. Bioanal. Chem., 410 (30), 7827-7835.

[6] Arya, S.K., Zhurauski, P., Jolly, P., Batistuti, M.R., Mulato, M., and Estrela, P., 2018, Capacitive aptasensor based on interdigitated electrode for breast cancer detection in undiluted human serum, Biosens. Bioelectron., 102, 106-112.

[7] Vondeling, G.T., Menezes, G.L., Dvortsin, E.P., Jansman, F.G.A., Konings, I.R., Postma, M.J., and
Rozenbaum, M.H., 2018, Burden of early, advanced and metastatic breast cancer in The Netherlands, BMC Cancer, 18 (1), 262.

[8] Huang, Y., Xu, J., Liu, J., Wang, X., and Chen, B., 2017, Disease-related detection with electrochemical biosensors: A review, Sensors, 17 (10), 2375.

[9] Lai, C., Liu, S., Zhang, C., Zeng, G., Huang, D., Qin, L., Liu, X., Yi, H., Wang, R., Huang, F., Li, B., and $\mathrm{Hu}, \mathrm{T}$., 2018, Electrochemical aptasensor based on sulfur-nitrogen codoped ordered mesoporous carbon and thymine- $\mathrm{Hg}^{2+}$-thymine mismatch structure for $\mathrm{Hg}^{2+}$ detection, ACS Sens., 3 (12), 2566-2573.

[10] Liu, S., Lai, C., Liu, X., Li, B., Zhang, C., Qin, L., Huang, D., Yi, H., Zhang, M., Li, L., Wang, W., Zhou, X., and Chen, L., 2020, Metal-organic frameworks and their derivatives as signal amplification elements for electrochemical sensing, Coord. Chem. Rev., 424, 213520.

[11] Hartati, Y.W., Gaffar, S., Alfiani, D., Pratomo, U., Sofiatin, Y., and Subroto, T., 2020, A voltammetric immunosensor based on gold nanoparticle - Anti$\mathrm{ENaC}$ bioconjugate for the detection of epithelial sodium channel $(\mathrm{ENaC})$ protein as a biomarker of hypertension, Sens. Bio-Sens. Res., 29, 100343.

[12] Cai, G., Yu, Z., Ren, R., and Tang, D., 2018, Excitonplasmon interaction between AuNPs/graphene nanohybrids and $\mathrm{CdS}$ quantum $\operatorname{dots} / \mathrm{TiO}_{2}$ for photoelectrochemical aptasensing of prostatespecific antigen, ACS Sens., 3 (3), 632-639.

[13] Hartati, Y.W., Komala, D.R., Hendrati, D., Gaffar, S., Hardianto, A., Sofiatin, Y., and Bahti, H.H., 2021, An aptasensor using ceria electrodepositedscreen-printed carbon electrode for detection of epithelial sodium channel protein as a hypertension biomarker, R. Soc. Open Sci., 8 (2), 202040.

[14] Parashar A., 2016, Aptamers in therapeutics, J. Clin. Diagn. Res.,10 (6), BE01-BE06.

[15] Kinghorn, A.B., and Tanner, J.A., 2017, Selective phenome growth adapted model: A novel landscape to represent aptamer ligand binding, Complexity, $2017,6760852$. 
[16] Trausch, J.J., Shank-Retzlaff, M., and Verch, T., 2017, Replacing antibodies with modified DNA aptamers in vaccine potency assays, Vaccine, 35 (41), 5495-5502.

[17] Drabovich, A.P., Berezovski, M., Okhonin, V., and Krylov, S.N., 2006, Selection of smart aptamers by methods of kinetic capillary electrophoresis, Anal. Chem., 78 (9), 3171-3178.

[18] Yufa, R., Krylova, S.M., Bruce, C., Bagg, E.A., Schofield, C.J., and Krylov, S.N., 2015, Emulsion PCR significantly improves nonequilibrium capillary electrophoresis of equilibrium mixtures-based aptamer selection: Allowing for efficient and rapid selection of aptamer to unmodified $\mathrm{ABH} 2$ protein, Anal. Chem., 87 (2), 1411-1419.

[19] Chun, L., Kim, S.E., Cho, M., Choe, W.S., Nam, J., Lee, D.W., and Lee, Y., 2013, Electrochemical detection of HER2 using single stranded DNA aptamer modified gold nanoparticles electrode, Sens. Actuators, B, 186, 446-450.

[20] Bang, G.S., Cho, S., Lee, N., Lee, B.R., Kim, J.H., and Kim, B.G., 2013, Rational design of modular allosteric aptamer sensor for label-free protein detection, Biosens. Bioelectron., 39 (1), 44-50.

[21] Komala, D.R., Hardianto, A., Gaffar, S., and Hartati, Y.W., 2021, An epithelial sodium channel (ENaC)specific aptamer determined through structurebased virtual screening for the development of hypertension early detection system, Pharm. Sci., 27 (1), 67-75.

[22] Şahin, S., Caglayan, M.O., and Üstündağ, Z., 2020, Recent advances in aptamer-based sensors for breast cancer diagnosis: Special cases for nanomaterialbased VEGF, HER2, and MUC1 aptasensors, Microchim. Acta, 187 (10), 549.

[23] Ferreira, D.C., Batistuti, M.R., Junior, B.B., and Mulato, M., 2021, Aptasensor based on screenprinted electrode for breast cancer detection in undiluted human serum, Bioelectrochemistry, 137, 107586.

[24] Gu, C., Guo, C., Li, Z., Wang, M., Zhou, N., He, L., Zhang, Z., and Du, M., 2019, Bimetallic ZrHf-based metal-organic framework embedded with carbon dots: Ultra-sensitive platform for early diagnosis of HER2 and HER2-overexpressed living cancer cells, Biosens. Bioelectron., 134, 8-15.

[25] Yang, S., You, M., Zhang, F., Wang, Q., and He, P., 2018, A sensitive electrochemical aptasensing platform based on exonuclease recycling amplification and host-guest recognition for detection of breast cancer biomarker HER2, Sens. Actuators, B, 258, 796-802.

[26] Qureshi, A., Gurbuz, Y., and Niazi, J.H., 2015, Label-free capacitance based aptasensor platform for the detection of HER2/ErbB2 cancer biomarker in serum, Sens. Actuators, B, 220, 1145-1151.

[27] Ou, D., Sun, D., Lin, X., Liang, Z., Zhong, Y., and Chen, Z., 2019, A dual-aptamer-based biosensor for specific detection of breast cancer biomarker HER2 via flower-like nanozymes and DNA nanostructures, J. Mater. Chem. B, 7 (23), 3661-3669.

[28] Poturnayová, A., Dzubinová, L., Buríková, M., Bízik, J., and Hianik, T., 2019, Detection of breast cancer cells using acoustics aptasensor specific to HER2 receptors, Biosensors, 9 (2), 72.

[29] Chen, D., Wang, D., Hu, X., Long, G., Zhang, Y., and Zhou, L., 2019, A DNA nanostructured biosensor for electrochemical analysis of HER2 using bioconjugate of GNR@ Pd SSs-Apt-HRP, Sens. Actuators, B, 296, 126650.

[30] Hermanson, G.T., 2013, Bioconjugate Techniques, $3^{\text {rd }}$ Ed., Academic Press, Cambridge, US.

[31] Hartati, Y.W., Nurdjanah, D., Wyantuti, S., Anggraeni, A., and Gaffar, S., 2018, Gold nanoparticles modified screen-printed immunosensor for cancer biomarker HER2 determination based on anti HER2 bioconjugates, AIP Conf. Proc., 2049, 020051.

[32] Emami, M., Shamsipur, M., Saber, R., and Irajirad, R., 2014, An electrochemical immunosensor for detection of a breast cancer biomarker based on antiHER2-iron oxide nanoparticle bioconjugates, Analyst, 139 (11), 2858-2866.

[33] Hartati, Y.W., Letelay, L.K., Gaffar, S., Wyantuti, S., and Bahti, H.H., 2020, Cerium oxide-monoclonal antibody bioconjugate for electrochemical 
immunosensing of HER2 as a breast cancer biomarker, Sens. Bio-Sens. Res., 27, 100316.

[34] Zuker, M., 2003, Mfold web server for nucleic acid folding and hybridization prediction, Nucleic Acids Res., 31 (13), 3406-3415.

[35] Jeddi, I., and Saiz, L., 2017, Three-dimensional modeling single stranded DNA hairpins for aptamerbased biosensor, Sci Rep., 7 (1), 1178.

[36] Jossinet, F., Ludwig, T.E., and Westhof, E., 2010, Assemble: An interactive graphical tool to analyze and build RNA architectures at the $2 \mathrm{D}$ and $3 \mathrm{D}$ levels, Bioinformatics, 26 (16), 2057-2059.

[37] Pettersen, E.F., Goddard, T.D., Huang, C.C., Couch, G.S., Greenblatt, D.M., Meng, E.C., and Ferrin, T.E., 2004, UCSF Chimera-A visualization system for exploratory research and analysis, J. Comput. Chem., 25 (13), 1605-1612.

[38] BIOVIA, Dassault Systèmes 2016, BIOVIA Discovery Studio Visualizer 4.5, v.16.1.0.15350, Dassault Systèmes, San Diego.

[39] Dolinsky, T.J., Nielsen, J.E., McCammon, J.A., and Baker, N.A., 2004, PDB2PQR: An automated pipeline for the setup of Poisson-Boltzmann electrostatics calculations, Nucleic Acids Res., 32 (Suppl. 2), W665-W667.

[40] Tuszynska, I., Magnus, M., Jonak, K., Dawson, W., and Bujnicki, J.M., 2015, NPDock: A web server for protein-nucleic acid docking, Nucleic Acids Res., 43 (W1), W425-W430.

[41] Miller, J.N., and Miller, J.C., 2005, Statistics and Chemometrics for Analytical Chemistry, $5^{\text {th }}$ Ed., Pearson Prentice Hall, England.

[42] Hartati, Y.W., Beladona, S.U.M., Wyantuti, S., and Gaffar, S., 2018, A voltammetric immunosensor for detection of HER2 using gold modified-screen printed carbon electrode, Res. J. Chem. Environ., 22, 294-301.

[43] Al-Khafaji, Q.A.M., Harris, M., Tombelli, S., Laschi, S., Turner, A.P.F., Mascini, M., and Marazza, G., 2012, An Electrochemical immunoassay for HER2 detection, Electroanalysis, 24 (4), 735-742.

[44] Kim, S.E., and Choe, W.S., 2011, Screening of ssDNA aptamers for HER2 ECD protein, Proc. Korean Soc. Biotechnol. Bioeng., 291. 